\title{
Ambipolar Organic Field-Effect Transistors Based on Indigo Derivatives
}

\author{
Oratai Pitayatanakul ${ }^{1, a}$, Kodai Iijima ${ }^{1}$, Tomofumi Kadoya ${ }^{1}$, Minoru Ashizawa ${ }^{1}$, \\ Tadashi Kawamoto $^{1}$, Hidetoshi Matsumoto ${ }^{1}$, and Takehiko Mori ${ }^{1,2, b}$ \\ 1 Department of Organic and Polymeric Materials, Tokyo Institute of Technology, O-okayama, Meguro-ku, \\ Tokyo, 152-8552, Japan. \\ 2 ACT-C, JST, Honcho, Kawaguchi, Saitama 332-0012, Japan. \\ E-mail: apitayatanakul.o.aa@m.titech.ac.jp, bmori.t.ae@m.titech.ac.jp (Corresponding author)
}

\begin{abstract}
In order to improve the ambipolar performance of indigo-based semiconductors, we have investigated halogen-substituted (1 - 4) and phenyl-substituted (5) indigo derivatives at the 5-position. We show that introduction of iodine atoms, namely 5,5'-diiodoindigo (4), leads to the strong halogen-halogen interaction (iodine-iodine interaction) that gives a significant effect on the molecular packing. Thanks to the supramolecular network coming from the extra iodine-iodine interaction, the molecules are arranged approximately perpendicular to the substrate in the thin film. This results in remarkable transistor performance of the maximum hole and electron mobilities $\left(\mu_{\mathrm{h}} / \mu_{\mathrm{e}}\right)=$ $0.42 / 0.85 \mathrm{~cm}^{2} \mathrm{~V}^{-1} \mathrm{~s}^{-1}$, which are one of the highest among small-molecule ambipolar organic transistors. Furthermore, introducing phenyl groups, $\mathbf{5}$ improves the transistor performances up to the maximum mobilities $\mu_{\mathrm{h}} / \mu_{\mathrm{e}}=0.56 / 0.95 \mathrm{~cm}^{2} \mathrm{~V}^{-1} \mathrm{~s}^{-1}$. We have found that the phenyl groups destroy the standard molecular packing of indigo to achieve a unique structure that is a hybrid of the herringbone and brickwork structures.
\end{abstract}

Keywords: Organic transistor, ambipolar, organic semiconductor, natural material.

ENGINEERING JOURNAL Volume 19 Issue 3

Received 27 May 2015

Accepted 27 May 2015

Published 5 June 2015

Online at http://www.engj.org/

DOI:10.4186/ej.2015.19.3.61 


\section{Introduction}

In the recent years, organic semiconductors have attracted much attention because of low-cost and easy fabrication to large-area and mechanically flexible substrates that are now used as active elements in optoelectronic devices such as organic light emitting diode (OLED), organic photonics, organic solar cells, and organic field effect transistors (OFETs). Organic semiconductors are usually classified as either p-type or n-type. A number of excellent p-type organic semiconductors showing mobilities higher than $1 \mathrm{~cm}^{2} \mathrm{~V}^{-1} \mathrm{~s}^{-}$ 1 have been developed, which are almost comparable to that of amorphous silicon. ${ }^{1,2}$ Examples are pentacene as a thin-film material $\left(0.3-0.7 \mathrm{~cm}^{2} \mathrm{~V}^{-1} \mathrm{~s}^{-1}\right.$ on a Si/SiO${ }_{2}$ substrate, ${ }^{1} 1.5 \mathrm{~cm}^{2} \mathrm{~V}^{-1} \mathrm{~s}^{-1}$ on a chemically modified $\mathrm{Si} / \mathrm{SiO}_{2}$ substrate), ${ }^{3}$ and rubrene as a single-crystal material $\left(\sim 20 \mathrm{~cm}^{2} \mathrm{~V}^{-1} \mathrm{~s}^{-1}\right) \cdot{ }^{4}$ Recently, excellent p-type characteristics are achieved using 2,7-dialkyl[1] benzothieno[3,2- b][1]benzothiophenes $\left(\mathrm{C}_{\mathrm{n}}\right.$-BTBTs). ${ }^{5}$ A high mobility of $16 \mathrm{~cm}^{2} \mathrm{~V}^{-1} \mathrm{~s}^{-1}$ has been attained in the printed thin-film transistors using $\mathrm{C}_{8}$-BTBT. ${ }^{6}$ Organic n-type organic semiconductors are represented by fullerene $\left(\mathrm{C}_{60}, 6.0 \mathrm{~cm}^{2} \mathrm{~V}^{-1} \mathrm{~s}^{-1}\right), 7$ perfluorinated copper phthalocyanine $\left(\mathrm{F}_{16} \mathrm{CuPc}, 0.03 \mathrm{~cm}^{2} \mathrm{~V}^{-1} \mathrm{~s}^{-1}\right),{ }^{8}$ and cycloalkyl naphtalene tetracarboxylic diimide (Cy6NTCDI, $\left.6.2 \mathrm{~cm}^{2} \mathrm{~V}^{-1} \mathrm{~s}^{-1}\right) .{ }^{9} \mathrm{P}$-type OFETs have been achieved in various organic semiconductors, but $\mathrm{n}$-type OFETs are still relatively limited. Recently, OFETs capable of both hole and electron transports have been realized; such transistors are called ambipolar transistors. Ambipolar transistors are essential for the development of integrated microelectronic organic circuits and optoelectronic devices. In principle, there are two ways to achieve ambipolar transport. One is the fabrication of mixed p-type and n-type materials, where the charge carrier mobilities are balanced by the mixing ratio. Another is the treatment of the substrate with a passivation layer such as tetratetracontane (TTC, $\mathrm{C}_{44} \mathrm{H}_{90}$ ). TTC is a long-chain alkane molecule that has a low dielectric constant that reduces polarization effects in the dielectric. The high surface energy increases the crystallinity of the semiconductor layer and improves the charge carrier transport. ${ }^{10-13}$ TTC has been recently used in OFETs and proved to be an excellent passivation layer to achieve ambipolar transistors. ${ }^{10-13}$ Second is the using of ambipolar organic semiconductors that are represented by donor-acceptor polymers including diketopyrrolopyrole (DPP), which show hole and electron field-effect mobilities $\left(\mu_{\mathrm{h}}\right.$ and $\mu_{\mathrm{e}}$ ) exceeding $1 \mathrm{~cm}^{2} \mathrm{~V}^{-1} \mathrm{~s}^{-1} .14$ For example, a polymer of thienothiophene and DPP that shows $\mu_{\mathrm{h}} / \mu_{\mathrm{e}}=1.36 / 1.56 \mathrm{~cm}^{2} \mathrm{~V}^{-1} \mathrm{~s}^{-1} .{ }^{15}$ Here, the thiophene moiety is regarded as the donor part carrying holes, and DPP is recognized as the acceptor part mediating the electron transport. Ambipolar transport has been also achieved in some small-molecule organic semiconductors such as quinoidal oligothiophenes, ${ }^{16-18}$ fullerenes, ${ }^{19,20}$ phthalocyaniones ${ }^{10-12,21,22}$ metal complexes, ${ }^{23}$ and even pentacene. ${ }^{11,24}$ Among these materials, $\mu_{\mathrm{h}} / \mu_{\mathrm{e}}=3 / 3 \mathrm{~cm}^{2} \mathrm{~V}^{-1} \mathrm{~s}^{-1}$ has been reported in a pentacene ambipolar transistor, ${ }^{24}$ but mobilities of other small-molecule ambipolar transistors are still lower than $1 \mathrm{~cm}^{2} \mathrm{~V}^{-1} \mathrm{~s}^{-1}$. Recently, it has been reported that even the small-molecule DPP derivatives show ambipolar performance with $\mu_{\mathrm{h}} / \mu_{\mathrm{e}}=0.01 \sim 0.06 \mathrm{~cm}^{2} \mathrm{~V}^{-1} \mathrm{~s}^{-1} .25 \mathrm{DPP}$ is the representative acceptor part in donor-acceptor polymers, but it becomes apparent that it works as an ambipolar organic semiconductor. The ambipolar performance of DPP is attributed to the electron-donating nitrogen atoms (-NH) working as a donor and the electron-withdrawing carbonyl groups $(-\mathrm{C}=\mathrm{O})$ as an acceptor. ${ }^{15}$ In addition, the intermolecular interaction mediated by the hydrogen bonding $(-\mathrm{NH} \cdots \mathrm{O}=\mathrm{C}-)$ has a significant effect on the molecular packing so as to improve the mobilities. ${ }^{26,27}$ A majority of donor-acceptor polymers prepared until now contain the DPP unit, but other units such as isoindigo have been attempted. Recently, it has been proved that small-molecule isoindigo also shows ambipolar transistor characteristics. ${ }^{28}$ Therefore, it is interesting to explore ambipolar transport in similar kinds of small molecules as an attempt to develop new acceptor units of donor-acceptor polymers as well as to develop small-molecule ambipolar organic semiconductors.

Recently, it has been reported that indigo $\left(\mu_{\mathrm{h}} / \mu_{\mathrm{e}}=0.01 / 0.01 \mathrm{~cm}^{2} \mathrm{~V}^{-1} \mathrm{~s}^{-1}\right)^{29}$ and Tyrain purple $\left(6,6^{\prime}-\right.$ dibromoindigo, $\left.\mu_{\mathrm{h}} / \mu_{\mathrm{e}}=0.40 / 0.40 \mathrm{~cm}^{2} \mathrm{~V}^{-1} \mathrm{~s}^{-1}\right)^{30,31}$ make good ambipolar OFET showing high and wellbalanced electron and hole mobilities. Indigo is a dye produced from the plant Indigofera tinctoria and Isatis tintora, which have been cultivated for at least four thousand years in China, India, and Egypt for coloring textiles. Indigo has an extremely low solubility and a high melting point $\left(390 \sim 392^{\circ} \mathrm{C}\right)$, explained by stabilization from inter- and intramolecular hydrogen bonding. Intermolecular interactions of $\pi$-skeletons also strongly influence the charge transport in indigo thin films. Similarly to the DPP derivatives, hydrogen bonded semiconducting molecules like indigo achieve high ambipolar performance. ${ }^{29-34}$ Indigo is of interest not only as a biological and bio-inspired material but also because of the minimal molecular structure 
consisting of electron-donating nitrogen atoms working as a donor and electron- withdrawing carbonyl groups as an acceptor. ${ }^{26}$ The characteristic blue color comes from the small energy gap, and the resulting long-wavelength absorption is closely related to the ambipolar transport. More recently, several halogensubstituted indigo derivatives have been reported, where the introduction of the halogen atoms $(\mathrm{F}, \mathrm{Cl}$, and $\mathrm{Br}$ ) to the 5-positions (1 - $\mathbf{3}$ in Fig. 1) induces the bathochromic shifts to reduce the energy gaps. ${ }^{34}$

a

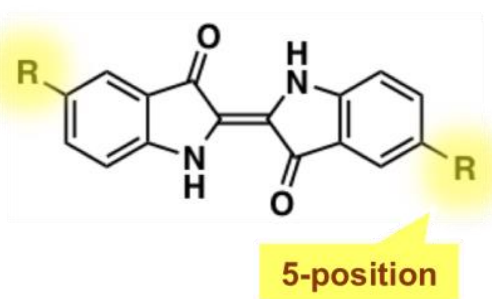

$\mathbf{R}=$

$\begin{array}{ll}\mathrm{F} & 1 \\ \mathrm{Cl} & 2 \\ \mathrm{Br} & 3 \\ \mathrm{I} & 4 \\ \mathrm{Ph} & 5\end{array}$

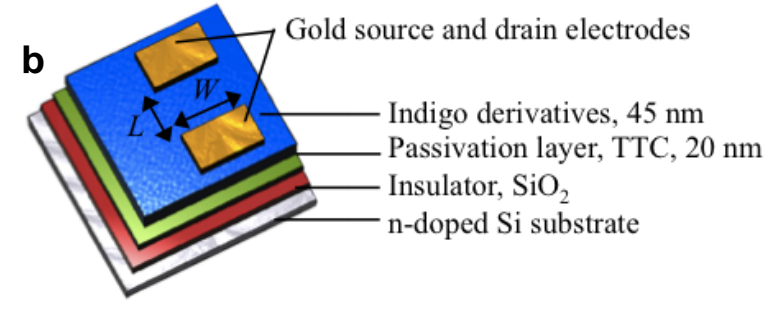

Fig. 1. (a) Structures of indigo derivatives. (b) Structure of an indigo field-effect transistor in bottom-gate top-contact geometry, where $L$ and $W$ are 100 and $1000 \mu \mathrm{m}$, respectively.

In the present work, in order to improve the ambipolar performance of indigo-based semiconductors, we have investigated halogen-substituted and phenyl-substituted indigo derivatives at the 5-position. We show that introduction of iodine atoms (4), remarkably improves the transistor properties. Polarizing power of a halogen atom increases in the order of $\mathrm{F}<\mathrm{Cl}<\mathrm{Br}<\mathrm{I}$, and iodine has particularly strong polarizing power among the halogen atoms. Accordingly, iodine atoms mediate halogen-halogen interactions and halogen bonds, and sometimes construct supramolecular architecture. ${ }^{35}$ Halogen bonds have been extensively investigated in the conducting cation-radical salts based on tetrathiafulvalene (TTF) derivatives, where the halogen-halogen interaction shows a significant effect on the molecular packing. ${ }^{36}$ In the chargetransfer salts, a halogen atom substituted on the TTF skeleton makes a close contact with such an anion as $\mathrm{Cl}^{-}, \mathrm{Br}^{-}$, and $\mathrm{CN}^{-}$to form characteristic molecular packing. It has been also attempted to include the third component such as diiodoacethylene and $p$-bis(iodoethynyl)benzene, where the iodine atom makes a contact with $\mathrm{Cl}^{-}$and $\mathrm{Br}^{-}$anions to construct supramolecular assembly. ${ }^{35}$ In the crystals of neutral TTF, it has been demonstrated that the halogen-halogen contact gives a significant effect on the molecular packing. 37a In this analogy, here we show the iodine substitution produces remarkable supramolecular interaction that improves the transistor performance. On the other hand, it has been reported that biphenyl substituted bithiophene ${ }^{38}$ as well as phenyl fused TTF ${ }^{39}$ show improved OFET properties. These results demonstrate that the phenyl substitution achieves a more parallel molecular packing and improves the FET performance. ${ }^{40,41}$ Then we have prepared 5-phenyl indigo (5). This compound has a new type of molecular packing that is a hybrid of the herringbone and brickwork packings, and exhibits a significantly improved transistor performance. We also report an ambipolar transistor of diphenyl indigo fabricated on an organic substrate, polyethylenenaphtalate (PEN), where polychloroparaxylylene (Parylene C) is proved to be an inert enough gate dielectric to achieve ambipolar transport.

\section{Results and Discussion}

\subsection{Electrochemical Properties}

The electronic structures are investigated by cyclic voltammetry (CV) and ultraviolet-visible spectroscopy (UV-Vis). The highest occupied molecular orbital (HOMO) level is estimated from the oxidation potential, $E_{o x}$, and the lowest unoccupied molecular orbital (LUMO) level is obtained from the reduction potential, $E_{\text {red }}$ (Table 1). The energy gaps $\left(E_{\mathrm{g}}\right)$ are estimated from the absorption edges of the ultraviolet-visible spectra (UV-Vis) measured in about $20 \mathrm{~nm}$ of thin films evaporated on a glass substrate. In comparison with the parent indigo, the halogen substitution at the 5,5'-positions leads to weak bathochromic shifts of the absorption spectra (Table 1).26,34 Figure 2 summarizes the resulting HOMO levels and LUMO levels including the calculated HOMO and LUMO levels by using Gaussian 09 package at B3LYP/CEP-31G level for $\mathbf{1}-\mathbf{4}$ and B3LYP/6-31G level for $\mathbf{5}$. The LUMO is located mostly on the carbonyl groups, while the HOMO spreads to the outer substituents, so that the substitution affords a larger effect on the HOMO level than the LUMO level. This is also verified by the redox potentials, where the LUMO level remains unchanged in comparison with the HOMO level. As a result, the substitution by heavy substituent atoms 
leads to more delocalized HOMO, to reduce $E_{\mathrm{g}}$ in the order of $\mathbf{1}(\mathrm{F})>\mathbf{2}(\mathrm{Cl})>\mathbf{3}(\mathrm{Br})>\mathbf{4}(\mathrm{I}) \sim \mathbf{5}(\mathrm{Ph})$. However, the absorption of $\mathbf{5}$ is not much different from that of others, suggesting that the $\pi$-skeleton is not really extended because, as will be verified from the crystal structure, the phenyl rings are not coplanar to the indigo part. It has been reported that using gold $(\mathrm{Au})$ source and drain electrodes, ambipolar transport is realized when the HOMO level is $>-5.6 \mathrm{eV}$ and the LUMO level is $<-3.2 \mathrm{eV}$. ${ }^{42}$ The estimated HOMO and LUMO levels of $\mathbf{3}$ - $\mathbf{4}$ satisfy these conditions, but the HOMO levels of $\mathbf{1}$ and $\mathbf{2}$ are obviously out of this range.

Table 1. Redox potentials and energy levels of $\mathbf{1}-\mathbf{5}$, and the parent indigo.

\begin{tabular}{lcccccr}
\hline Compounds & $\begin{array}{c}\boldsymbol{E}_{\text {ox }} \\
{[\mathbf{V}]}\end{array}$ & $\begin{array}{c}\boldsymbol{E}_{\text {red }} \\
{[\mathbf{V}]}\end{array}$ & $\begin{array}{c}\text { HOMO } \\
{[\mathrm{eV}]}\end{array}$ & $\begin{array}{c}\text { LUMO } \\
{[\mathrm{eV}]}\end{array}$ & $\begin{array}{c}\text { HOMO-LUMO gap } \\
{[\mathrm{eV}]}\end{array}$ & $\begin{array}{r}\text { Optical gap (thin film) } \\
{[\mathrm{eV}]}\end{array}$ \\
\hline $\mathbf{1}(\mathrm{F})^{\mathrm{a}}$ & 0.96 & -0.89 & 5.76 & 3.94 & 1.82 & 1.66 \\
$\mathbf{2}(\mathrm{Cl})^{\mathrm{b}}$ & 0.99 & -0.84 & 5.79 & 3.96 & 1.83 & 1.72 \\
$\mathbf{3}(\mathrm{Br})^{\mathrm{c}}$ & 0.85 & -0.94 & 5.65 & 3.86 & 1.79 & 1.71 \\
$\mathbf{4}(\mathrm{I})^{\mathrm{b}}$ & 0.79 & -0.86 & 5.59 & 3.94 & 1.65 & 1.68 \\
$\mathbf{5}(\mathrm{Ph})^{\mathrm{c}}$ & 0.76 & -0.89 & 5.56 & 3.91 & 1.65 & 1.70 \\
Indigo & 0.80 & -0.89 & 5.60 & 3.91 & 1.69 & $1.7(\mathrm{ref.} 29)$ \\
\hline
\end{tabular}

Onset redox potentials $v s$. $\mathrm{Fc} / \mathrm{Fc}^{+}$are assumed to be $4.8 \mathrm{eV}$ from the vacuum level. ${ }^{42}$

${ }^{\mathrm{a}} \mathrm{Fc} / \mathrm{Fc}^{+}: \mathrm{E}^{1 / 2}=+0.190 \mathrm{~V}$

${ }^{\mathrm{b}} \mathrm{Fc} / \mathrm{Fc}^{+}: \mathrm{E}^{1 / 2}=+0.213 \mathrm{~V}$

${ }^{\mathrm{c}} \mathrm{Fc} / \mathrm{Fc}^{+}: E^{1 / 2}=+0.31 \mathrm{~V}$

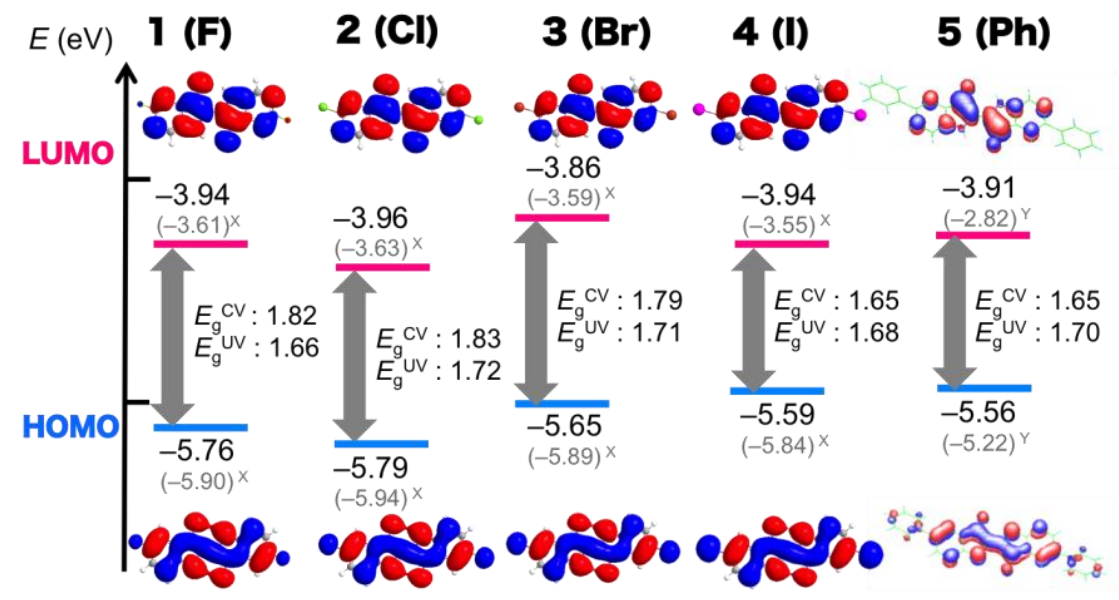

Fig. 2. Energy levels of $\mathbf{1}$ - $\mathbf{5}$ estimated from the redox potentials and from the Gaussian 09 calculation at the B3LYP/CEP-31G level ${ }^{\mathrm{X}, 43}$ for $\mathbf{1}$ - $\mathbf{4}$ and the B3LYP/6-31G levelY for $\mathbf{5}$ in the parentheses.

\subsection{Transistor Characteristics}

The transistors were fabricated on a heavily doped n-type silicon substrate $\left(300 \mathrm{~nm}\right.$ of $\mathrm{SiO}_{2}$ as a gate dielectric) with a $20 \mathrm{~nm}$ passivation layer of tetratetracontane (TTC, $\mathrm{C}_{44} \mathrm{H}_{90}$, Fig. 1(b)). Long alkyl-chain molecules like TTC were advantageous in ambipolar transport due to the low dielectric constant, reduced polarlization effect, and the improved crystallinity of the semiconductor layer. ${ }^{10-13}$ The indigo derivatives of about $45 \mathrm{~nm}$ thickness were deposited by vacuum evaporation, on which gold source and drain electrodes were formed to complete the bottom gate - top contact devices. The transfer and output characteristics were measured under vacuum (Fig. 3). The mobilities were extracted from the square root of the drain current $\left(I_{\mathrm{D}}\right)$ in the transfer characteristics by using the formulas of the unipolar saturated region as listed in Table 2.

Compounds 1 and 2 show only n-type transport, where the maximum mobilities are $\mu_{\mathrm{e}}=1.7 \times 10^{-3}$ and $0.022 \mathrm{~cm}^{2} \mathrm{~V}^{-1} \mathrm{~s}^{-1}$, respectively. This is in agreement with the electronegative nature of 1 and $2 .{ }^{34}$ The threshold voltages $\left(V_{\mathrm{TH}}\right)$ of $\mathbf{1}$ and $\mathbf{2}$ are estimated to be $19 \mathrm{~V}$ and $33 \mathrm{~V}$, respectively. The transfer characteristics of $\mathbf{3}$ - $\mathbf{5}$ (Figures 16c - e) shows clear ambipolar characteristics, which affords very high and well-balanced mobilities of $\mu_{\mathrm{h}} / \mu_{\mathrm{e}}=0.21 / 0.35,0.42 / 0.85,0.56 / 0.95 \mathrm{~cm}^{2} \mathrm{~V}^{-1} \mathrm{~s}^{-1}$ (Table 2). ${ }^{33}$ Transistor 
performance of 3 is very similar to those of 6,6'-dibromoindigo, 33,34 including the sweep direction dependence of the mobilities. The mobility of the halogen-substituent compounds $(\mathbf{1}-\mathbf{4})$ decreases in the order of $4(\mathrm{I})>3(\mathrm{Br})>2(\mathrm{Cl})>1(\mathrm{~F})$, which is opposite to the electronegativity, but equal to the halogen size and the polarizing power. The order of mobility also coincides with the decreasing order of $E_{\mathrm{g}}$ (Fig. 2). There have been recently reported a few donor-acceptor polymers in which both electron and hole mobilities exceeding $1 \mathrm{~cm}^{2} \mathrm{~V}^{-1} \mathrm{~s}^{-1},{ }^{15}$ and a pentacene ambipolar transistor whose electron and hole mobilities are $3 \mathrm{~cm}^{2} \mathrm{~V}^{-1} \mathrm{~s}^{-1} .{ }^{24}$ However, mobilities of other small-molecule ambipolar transistors are still lower than 1 $\mathrm{cm}^{2} \mathrm{~V}^{-1} \mathrm{~s}^{-1}$, and the present values of $\mathbf{4}$ and $\mathbf{5}$ are one of the highest among the small-molecular ambipolar materials. ${ }^{15}$
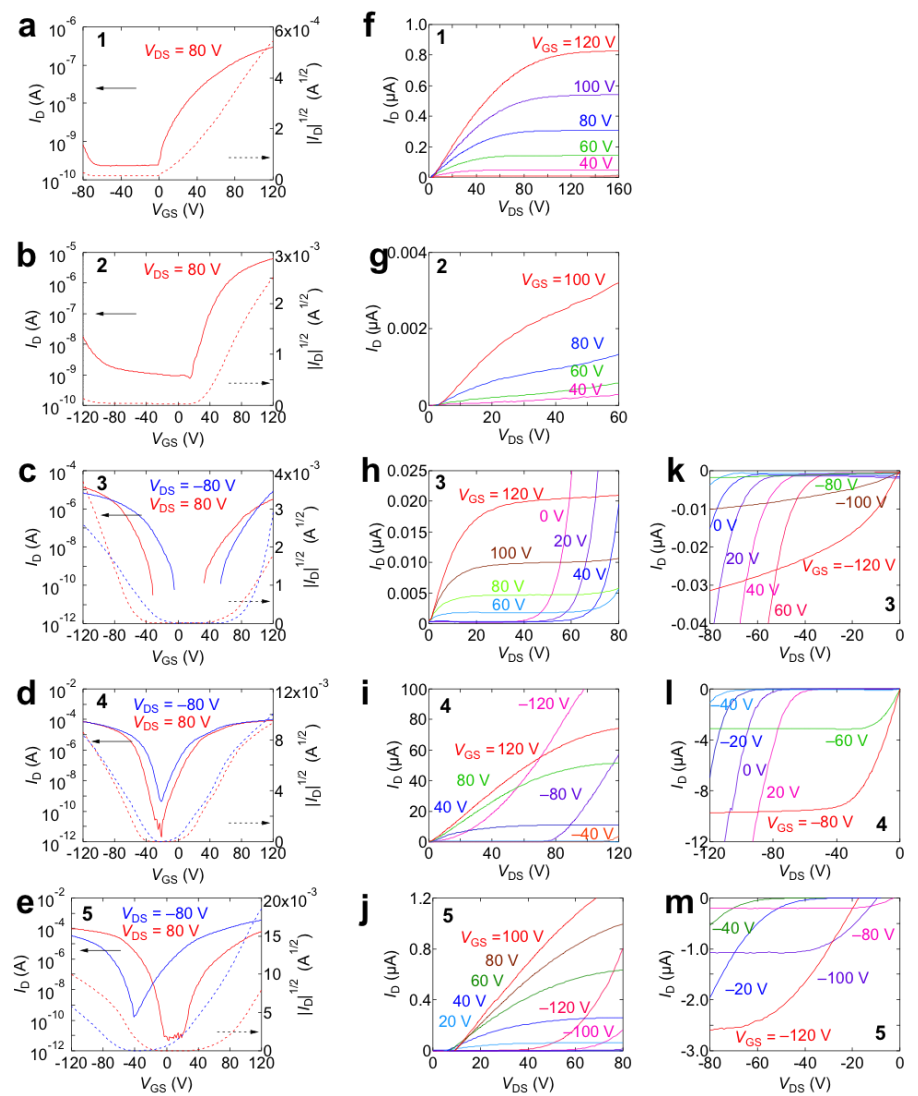

Fig. 3. (a-e) Transfer characteristics of $\mathbf{1} \mathbf{- 5}$. Output characteristics (f-j) at $V_{\mathrm{DS}}>0$ of thin-film transistors based on $\mathbf{1}-\mathbf{5}$ and $(\mathrm{k}-\mathrm{m})$ at $V_{\mathrm{DS}}<0$ of thin-film transistors based on $\mathbf{3}-\mathbf{5}$. All measurements are done under vacuum.

Table 2. Summary of mobilities of $\mathbf{1}$ - $\mathbf{5}$, and the parent indigo.

\begin{tabular}{|c|c|c|c|c|c|c|c|}
\hline \multirow[t]{2}{*}{ Compound } & \multirow[t]{2}{*}{$\overline{V_{D S}[\mathrm{~V}]}$} & \multicolumn{2}{|c|}{$\begin{array}{c}\text { Maximum mobilities } \\
\text { under vacuum } \\
{\left[\mathrm{cm}^{2} \mathrm{~V}^{-1} \mathrm{~s}^{-1}\right]}\end{array}$} & \multicolumn{2}{|c|}{$\begin{array}{c}\text { Average mobilities } \\
\text { under vacuum } \\
{\left[\mathrm{cm}^{2} \mathrm{~V}^{-1} \mathrm{~s}^{-1}\right]}\end{array}$} & \multicolumn{2}{|c|}{$\begin{array}{l}\text { Threshold Voltage } \\
\text { [V] }\end{array}$} \\
\hline & & Hole & Electron & Hole & Electron & Hole & Electron \\
\hline \multirow{2}{*}{$\begin{array}{l}1(\mathrm{~F}) \\
2(\mathrm{Cl})\end{array}$} & 80 & - & $1.7 \times 10^{-3}$ & - & $7.6 \times 10^{-4}$ & - & 19 \\
\hline & 80 & - & 0.022 & - & 0.012 & - & 33 \\
\hline \multirow[t]{2}{*}{$3(\mathrm{Br})$} & 80 & 0.21 & 0.04 & 0.08 & 0.03 & -58 & 71 \\
\hline & -80 & 0.07 & 0.35 & 0.02 & 0.27 & -31 & 97 \\
\hline \multirow[t]{2}{*}{4 (I) } & 80 & 0.57 & 0.85 & 0.30 & 0.48 & -46 & 15 \\
\hline & -80 & 0.42 & 0.75 & 0.16 & 0.35 & -34 & 11 \\
\hline \multirow[t]{2}{*}{$5(\mathrm{Ph})$} & 80 & 0.56 & 0.60 & 0.42 & 0.49 & -31 & 73 \\
\hline & -80 & 0.24 & 0.95 & 0.16 & 0.73 & -60 & 29 \\
\hline Indigo $^{29}$ & 10 & 0.01 & 0.01 & - & - & - & - \\
\hline
\end{tabular}




\subsection{Crystal Structures}

Crystal structure of $\mathbf{1}$ has been recently reported. ${ }^{34}$ Here, we show our data of crystal structures of 2 - $\mathbf{5}$ that are investigated by single-crystal X-ray structure analyses. Due to the poor solubility of these compounds in organic solvents, the crystals were grown by the sublimation method. Although all crystals belong to the same monoclinic space group $P 2_{1} / c$, only $\mathbf{2}$ and $\mathbf{3}$ are strictly isostructural, and $\mathbf{1}, \mathbf{4}$, and $\mathbf{5}$ are different from these structures. In all cases, the stacking direction corresponds to the crystallographic $b$ axis, and the molecular long axis is basically parallel to the $a$ axis. However, the arrangements of the stacks are different (Fig. 4 and 5). For $\mathbf{1}$ - 4, The interplanar spacing $\Delta$ increases as the size of the halogen substituent increases (Table 3); the difference is very slight from 1 to 3 , but $\mathbf{4}$ has a significantly large $\Delta$. The stacks are connected by hydrogen bonds with the N...O distance of $2.9 \AA$ and the H... O distance of $2.1 \AA$ in $4 .{ }^{44-47}$ For 1 , hydrogen bonding F...H with the distance of $2.464 \AA$ is found between the adjacent molecules along the molecular long axis (Fig. 4(a)). By contrast, no interaction is found in 2 along the molecular long axis. However, short halogen-halogen contacts with the distances of $3.611 \AA$ and $3.875 \AA$ are observed in 3 and 4 along the molecular long axis (Fig. 4(b)). These values are 2.4\% and 2.2\% shorter than the sum of the van der Waals radius $\left(3.70 \AA\right.$ for $\mathrm{Br} \ldots \mathrm{Br}$ and $3.96 \AA$ for I...I). ${ }^{37,48} \mathrm{In}$ comparison with 3 that shows one intermolecular $\mathrm{Br} . . \mathrm{Br}$ contact, 4 has two intermolecular I...I contacts (Fig. 4(d) and 4(e)). These halogen-halogen contacts connect molecules of different conducting layers along the $a$ axis. Along the $c$ axis, the adjacent stacks are alternately tilted in the opposite directions (Fig. 4(b)). The dihedral angle between the adjacent molecules $(a)$ and the tilt angle of the molecular long axis from the direction vertical to the stack direction ( $\beta$, Fig. 4(c)) are summarized in Table 3. These angles monotonously decrease from 1 to 4 . Since the molecules are slightly inclined from the stacking direction along the molecular short axis, $a=2 \beta$ does not hold except for $\mathbf{1}$. The molecular lengths $l$ of $\mathbf{1}-\mathbf{4}$ are estimated from the crystallographic $a$ and the tilt angle $\beta$ from $l=a / \cos \beta$ (Table 3). The lattice constant $b$ also decreases in the same order as $a$ and $\beta, 6.0281 \AA>4.54025 \AA>4.462 \AA>4.38905 \AA$. This implies that the molecule in 4 is most close to perpendicular to the stacking direction. The lattice constants $b$ of $\mathbf{2}$ to $\mathbf{4}$ are considerably smaller than the parent indigo, $b=5.77-5.88 \AA$ (depending on the polymorphism), ${ }^{33,44-47}$ indicating that the molecular long axis is less tilted from the stacking direction, and this is an origin of the enhanced mobility. However, the molecules of 4 are still by $34^{\circ}$ tilted from the stacking direction.

Compound $\mathbf{5}$ has a structure completely different from $\mathbf{1}-\mathbf{4}$ and the conventional indigo derivatives (Fig. 5). The phenyl planes are tilted by 29o from the central indigo plane. The phenyl groups form a perfect herringbone structure with the dihedral angle of $72 \circ$ (Fig. 5(c)). The indigo part is, however, approximately parallel to the ac plane; only slightly tilted by 70 from the $c$ axis. When this structure is regarded as a herringbone structure, the dihedral angle is as small as $14^{\circ}$ (Fig. 5(d)). The parallel molecules do not form stacks either along the $b$ axis or along the $c$ axis. If these indigo parts are regarded as approximately parallel to each other, this structure is recognized as a brickwork structure. ${ }^{49,50}$ Viewed from the central molecule at $y=1 / 2$, two molecules at $y=0$ are largely but equivalently displaced along the molecular short axis $(/ / c)$. Then the lattice constant $b$ is twice the interplanar distance of $3.50 \AA$. The hydrogen bond survives between the parallel molecules $(/ / c)$, though the $\mathrm{N}-\mathrm{O}$ distance of $3.1 \AA$ (and the $\mathrm{H}-\mathrm{O}$ distance of $2.4 \AA$ ) is slightly longer than the corresponding distance of $2.9 \AA$ (and the H-O distance of $2.1 \AA$ ) in $\mathbf{1}-\mathbf{4}$.

The transfer integrals in the stacking $(b)$ direction for HOMO and LUMO ( $\left.t_{\mathrm{HOMO} O} / t_{\mathrm{LUMO}}\right)$ are estimated from the molecular orbital calculation as shown in Table 3. In 4, the LUMO affords a large transfer, whereas the HOMO gives a small transfer. In addition, 4 has a particularly large transfer integral between halogen-halogen atoms, $t_{\mathrm{R}-\mathrm{R} \text {, номо }}=6.89 \mathrm{meV}$ along the molecular long axis (Fig. 4(e)). This is obviously due to the I...I interaction; the HOMO is most seriously influenced because the HOMO spread to the iodine atoms considerably (Fig. 2). Since this interchain interaction is comparable to the intrastack interaction in magnitude, there is a possibility that the charge transport of $\mathbf{4}$ is not confined in the stacking $(b)$ direction. Two-dimensional carrier transport is expected in 5. The brickwork structure has been observed in cyclohexyl naphthalene diimide which attain high field-effect mobility. ${ }^{49}$ Although the present structure is different from the ideal brickwork structure, the network of the transfer integrals is identical to the cyclohexyl naphthalene diimide. It is noteworthy that the present characteristic molecular packing, which is a hybrid of the herringbone and brickwork structure, is induced by the steric effect of the two phenyl 
groups. The incorporation of the phenyl groups elongates the molecules to destroy the twisted stack structure. The whole molecules realize a herringbone structure, but interestingly the central parts realize an approximate brickwork structure. The remarkably enhanced mobility of $\mathbf{5}$ is mainly attributed to this brickwork packing that realizes two-dimensional transport, rather than the extended $\pi$-skeleton coming from the introduction of the phenyl groups.
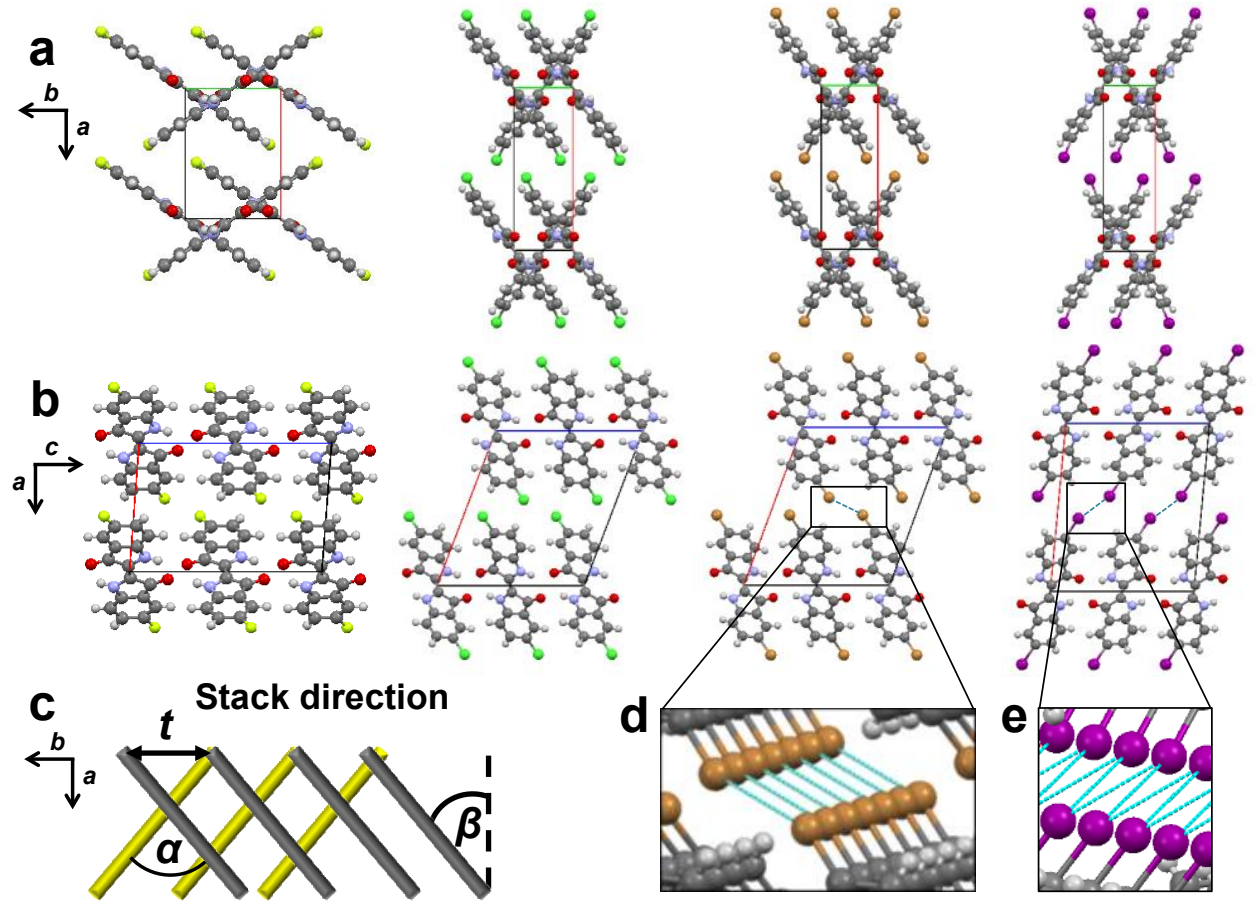

Fig. 4. Crystal structures of 1-4 viewed along the (a) $c$ and (b) $b$ axes. (c) Schematic illustration of the stacking structure. Halogen-halogen contacts of (d) 3 and (e) 4. The distances are $3.611 \AA$ and $3.875 \AA$, respectively.
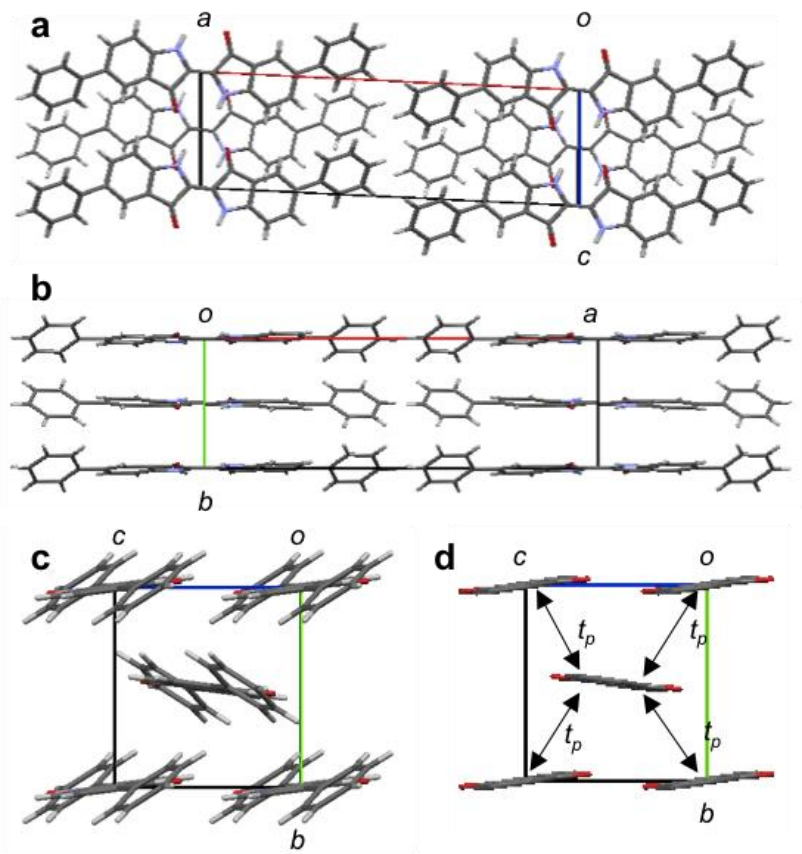

Fig. 5. Crystal structure of 2 viewed along the (a) b, (b) $c$, and (c), (d) $a$ axes. Hydrogen atoms and phenyl groups are omitted in (d). The transfer integral, $t_{\mathrm{p}}$, is estimated to be $20.4 \mathrm{meV}$ for HOMO and $23.5 \mathrm{meV}$ for LUMO. 
Table 3. Parameters extracted from the crystal and thin-film structures.

\begin{tabular}{llllll}
\hline Compound & $\mathbf{1}(\mathrm{F})^{34}$ & $\mathbf{2}(\mathrm{Cl})$ & $\mathbf{3}(\mathrm{Br})^{33}$ & $\mathbf{4}(\mathrm{I})$ & $\mathbf{5}(\mathrm{Ph})^{33}$ \\
\hline$\Delta(\AA)$ & 3.37 & 3.38 & 3.39 & 3.42 & 3.50 \\
$\alpha\left(^{\circ}\right)$ & 112 & 84 & 81 & 78 & 14 \\
$\beta\left(^{\circ}\right)$ & 56 & 37 & 36 & 34 & 0 \\
$l(\AA)$ & 14.8 & 16.7 & 17.1 & 17.0 & 21.3 \\
$t_{\mathrm{HOMO}} / t_{\mathrm{LUMO}}(\mathrm{meV})$ & $11.8 / 39.2$ & $12.2 / 12.6$ & $12.4 / 21.0$ & $2.96 / 35.3$ & $20.4 / 23.5$ \\
$t_{\mathrm{R}-\mathrm{R}, \mathrm{HOMO}}(\mathrm{meV})$ & 0.040 & 1.16 & 1.83 & 6.89 & 1.69 \\
\hline $2 \theta\left(^{\circ}\right)$ & 7.85 & 6.79 & 6.49 & 5.17 & 4.17 \\
$d(\AA)$ & 11.2 & 13.0 & 13.6 & 17.1 & 21.2 \\
$\beta^{\prime}\left({ }^{\circ}\right)$ & 41 & 39 & 37 & 0 & 5 \\
\hline
\end{tabular}

\subsection{Thin Film Properties}

Atomic force microscopy (AFM) images and X-ray diffraction (XRD) peaks of the thin films deposited on a TTC layer are shown in Fig. 6. The thin films of $\mathbf{1}-\mathbf{5}$ consist of highly crystalline domains due to the strong intermolecular interactions. This tendency is enhanced by the TTC passivation layer, because it has been reported in a wide variety of organic semiconductors that the crystallinity is improved on TTC. Accordingly, TTC plays a crucial role in the high mobility as well as the ambipolar charge transport. ${ }^{10-12}$

Figure $6(\mathrm{f})$ shows X-ray diffraction (XRD) peaks. The $2 \theta \square$ value decreases systematically from $\mathbf{1}$ to $\mathbf{5}$, and the corresponding $d$-value increases as shown in Table 3 . The $d$-values of $\mathbf{2}, \mathbf{3}$, and $\mathbf{5}$ approximately coincide with the crystallographic $a$ axis $(13.3166 \AA, 13.794 \AA$, and $21.2805 \AA)$. Thus the thin-film molecular packing is considered to be the same as the crystal structure. However, the $d$-values of $\mathbf{1}$ and $\mathbf{4}$ are larger than the crystallographic axes $(8.249 \AA$ and $14.0666 \AA)$, indicating the molecules are less tilted from the vertical direction in the thin films than in the crystals. In order to discuss this point more quantitatively, the molecular tilt angle in the thin film $(\beta$, Fig. $6(\mathrm{~g}))$ is calculated from $l=d / \cos \beta$, where $l$ is the molecule length estimated from the crystal structure. $\beta$ 'decreases in the same order as $\alpha$ and $\beta$. The values for $\mathbf{2 , 3}$, and $\mathbf{5}$ are not largely different from the values in the crystals. This indicates that the thin-film molecular packing is basically the same as the crystal structures. However, the values for $\mathbf{1}$ and $\mathbf{4}$ are significantly smaller than those in the crystals. In particular, 4 shows nearly perpendicular arrangement $\left(\beta^{\prime}=\right.$ $0^{\circ}$ ). Correlation of $\beta$ ' and the maximum electron mobility (Table 2) is depicted in Fig. $6(\mathrm{~g}){ }^{29,32,33}$ Mobilities of not only the present compounds but also the parent indigo and 6,6'-dibromoindigo show satisfactory correlation with the tilt angle in the thin films. This reminds us the naphthalene diimide (NDI) series compounds, where the charge mobility attains the maximum when the molecular long axis is exactly perpendicular to the substrate. ${ }^{48,50}$ Without assuming the thin-film structure different from the crystal structure, we have to attribute the high performance of 4 to the anomalous iodine-iodine electronic

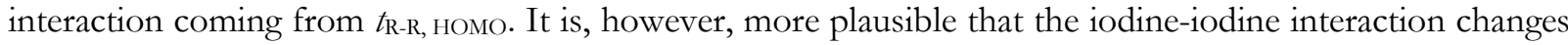
the thin-film structure, and the resulting perpendicular molecular arrangement realizes the high ambipolar performance comparable to 5 .
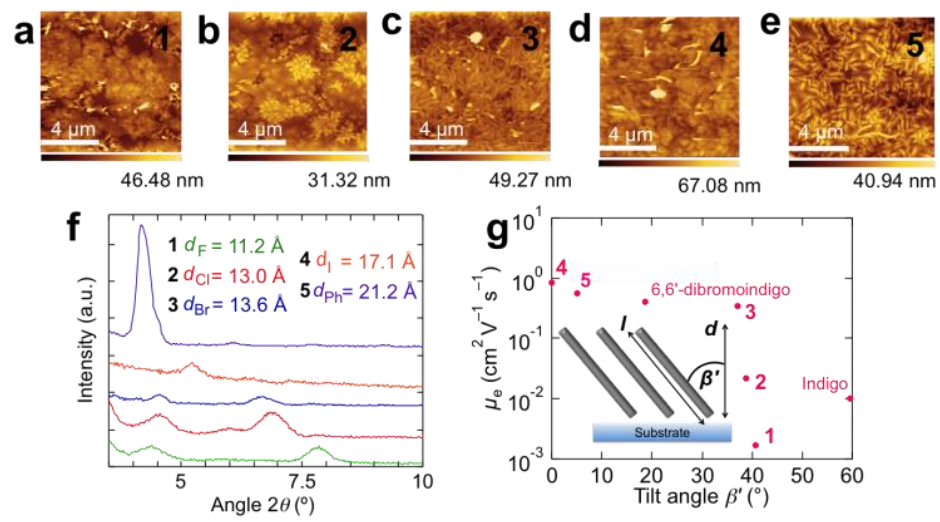

Fig. 6. AFM images of thin films of (a-e) 1 - 5. (f) XRD patterns of 1 - 5. (g) Correlation of the maximum electron mobility with the tilt angle of the molecule long axis to the substrate $(\beta)$. 


\subsection{Transistor on an organic substrate}

In order to explore a way to flexible devices, we have fabricated a transistor of $\mathbf{5}$ on an organic PEN substrate by using poly(3,4-ethylenedioxythiophene):poly(stylenesulfonate) (PEDOT:PSS) as a gate electrode, and a Parylene $\mathrm{C}$ film as gate dielectric (Fig. 7(a)). A pentacene transistor with the hole mobility of $0.3 \mathrm{~cm}^{2} \mathrm{~V}^{-1} \mathrm{~s}^{-1}$ has been reported using PEDOT:PSS as the gate contacts. ${ }^{51,52} \mathrm{~A}$ pentacene ambipolar transistor in a bottom-gate top-contact geometry has been realized by using Parylene $\mathrm{C}$ as the hydrophobic dielectric layer $\left(\mu_{\mathrm{h}} / \mu_{\mathrm{e}}=0.07-0.1 / 0.01-0.04 \mathrm{~cm}^{2} \mathrm{~V}^{-1} \mathrm{~s}^{-1}\right)$, so Parylene $\mathrm{C}$ is an inert enough material to achieve an ambipolar transistor. ${ }^{53}$ The XRD shows peaks at $d=$ $21.2 \AA$ and $6.33 \AA$ (Fig. 7(b)), which respectively correspond to 5 and Parylene C. ${ }^{54}$ As shown in Fig. $7(\mathrm{~d}-\mathrm{f})$, the transistor shows well-balanced ambipolar characteristics, where the maximum mobilities are $\mu_{\mathrm{h}} / \mu_{\mathrm{e}}=0.13 / 0.29 \mathrm{~cm}^{2} \mathrm{~V}^{-1} \mathrm{~s}^{-1}$. The AFM image (Fig. $7(\mathrm{c})$ ) reveals decreased grain size, which may be related to the reduced transistor performance. The hole/electron threshold voltages extracted from the transfer characteristics are $-25 / 120 \mathrm{~V}$ for $V_{\mathrm{DS}}=80 \mathrm{~V}$ and $-50 / 90 \mathrm{~V}$ for $V_{\mathrm{DS}}=$ $-80 \mathrm{~V}$. Although the threshold voltages are increased in comparison with the TTC transistors, Parylene $\mathrm{C}$ is a promising gate dielectric material for an ambipolar transistor.
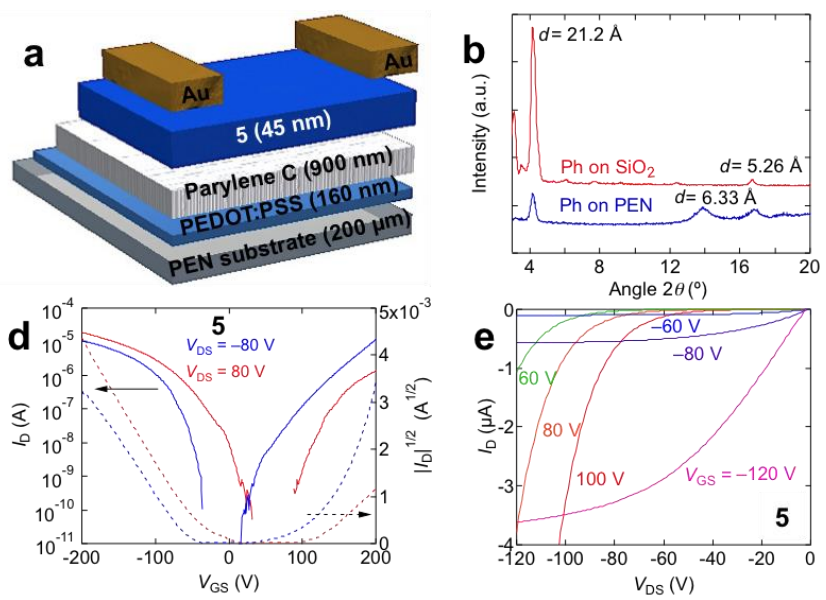

c
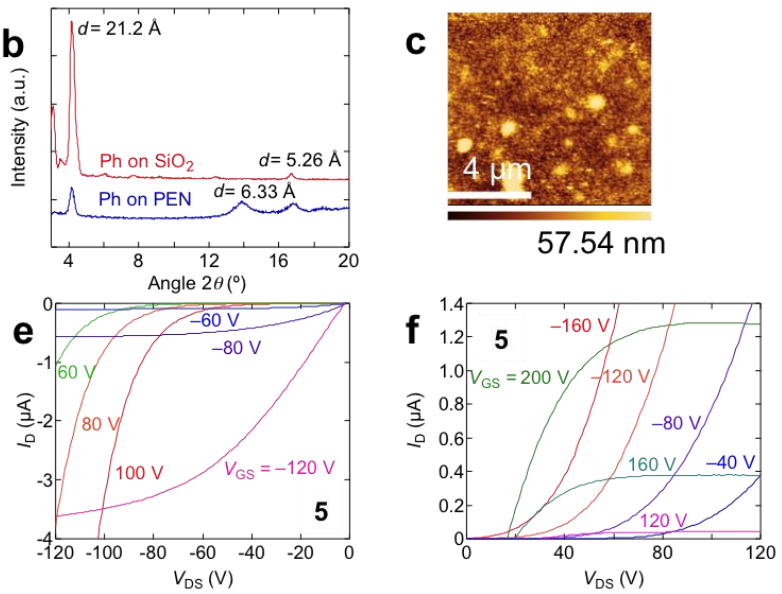

Fig. 7. (a) Structure of an indigo organic transistor on a PEN substrate in bottom-gate top-contact geometry, where $L$ and $W$ are 100 and $1000 \mu \mathrm{m}$, respectively. (b) XRD pattern of 5, (c) AFM image of a thin film of $5(45 \mathrm{~nm})$ deposited on a $900 \mathrm{~nm}$ film of Parylene C film. (d) Transfer characteristics of a thinfilm transistor of $\mathbf{5}$ on a PEN substrate. (e) Output characteristics at $V_{\mathrm{DS}}<0$, and (f) at $V_{\mathrm{DS}}>0$.

\section{Conclusion}

In summary, we have developed new indigo derivatives showing excellent ambipolar transistor properties. The diiodo-indigo 4 and the diphenyl-indigo 5 shows ambipolar transistor properties as high as $\mu_{\mathrm{h}} / \mu_{\mathrm{e}}=$ $0.42 / 0.85$ and $0.56 / 0.95 \mathrm{~cm}^{2} \mathrm{~V}^{-1} \mathrm{~s}^{-1}$, respectively. For 4 , the iodine-iodine interaction affords an extra interchain transfer integral as large as $6.89 \mathrm{meV}$ in the crystal, which is comparable to the intrachain interaction. However, the systematic change of the thin-film $d$-value suggests a nearly perpendicular molecular arrangement achieved in the thin film. In this case, the iodine-iodine interaction is suspected to play an important role in realizing the extraordinary arrangement. Since iodine-iodine contacts are universally observed in organic crystals, such supramolecular assembling power is indispensable to achieve the exceptional packing pattern in the indigo derivative. The present finding demonstrates that supramolecular engineering mediated by halogen-halogen interaction has great possibilities in organic semiconductors. In particular, the transistor performance of $\mathbf{5}$ stems from the characteristic structure that is a hybrid of the herringbone and brickwork structures in contrast to the stacking structure of the parent indigo. Another important aspect is the well-balanced ambipolar properties achieved by a molecule with a minimal $\pi$-framework. The present finding also suggests great possibilities of bio-inspired materials for the development of organic semiconductors. 


\section{Acknowledgement}

The authors are grateful to Tokyo Institute of Technology Center for Advanced Materials Analysis for XRD measurement, Prof. Kakimoto for NMR and AFM measurements, and Ass. Prof. Ishikawa for sublimation equipment. This work was partly supported by a Grant-in Aid for Scientific Research (B) (No. 23350061) from the Ministry of Education, Culture, Sports, Science, and Technology of Japan.

\section{References}

[1] H. E. Katz, Z. Bao, and S. L. Gilat, "Synthetic chemistry for ultrapure, processable, and high-mobility organic transistor semiconductors," Acc. Chem. Res., vol. 34, pp. 359-369, 2001.

[2] D. J. Gundlach, Y. Y. Lin, T. N. Jackson, S. F. Nelson, and D. G. Schlom, "Pentacene organic thinfilm transistors-molecular ordering and mobility," IEEE Electron device Lett., vol. 18, pp. 87-89, 1997.

[3] Y. Y. Lin, D. J. Gundlanch, S. F. Nelson, and T. N. Jackson, "Stacked pentacene layer organic thinfilm transistors with improved characteristics," IEEE Electron Device Lett., vol. 18, pp. 606-608, 1997.

[4] V. Podzorov, V. M. Pudalov, and M. E. Gerchenson, "Single-crystal organic field effect transistors with the hole mobility $\sim 8 \mathrm{~cm} 2 /$ Vs," Appl. Phys. Lett., vol. 82, pp. 3504-3506, 2003.

[5] (a) H. Ebata, T. Izawa, E. Miyazaki, K. Takimiya, M. Ikeda, H. Kuwabara and T. Yui, "Highly Soluble [1]Benzothieno[3,2-b] benzothiophene (BTBT) Derivatives for High-Performance, Solution-Processed Organic Field-Effect Transistors," J. Am. Chem. Soc., vol. 129, pp. 15732-15733; (b) T. Izawa, E. Miyazawa and K. Takimiya, "Molecular Ordering of High-Performance Soluble Molecular Semiconductors and Re-evaluation of Their Field-Effect Transistor Characteristics," Adv. Mater., vol. 20, pp. 3388-3392, 2008.

[6] H. Minemawari, Y. Toshikazu, H. Matui, J. Tsutsumi, S. Haas, R. Chiba, R. Kumai, and T. Hasegawa, "Inkjet printing of single-crystal films," Nature, vol. 475, pp. 364-367, 2011.

[7] Th. B. Singh, N. S. Sariciftci, H. Yang, L. Yang, B. Plochberger, and H. Sitter, "Correlation of crystalline and structural properties of $\mathrm{C}_{60}$ thin films grown at various temperature with charge carrier mobility," Appl. Phys. Lett., vol. 90, pp. 213512, 2007.

[8] Z. Bao, A. J. Lovinger, and J. Brpwn, "New Air-Stablen-Channel Organic Thin Film Transistors," J. Am. Chem. Soc., vol. 120, p. 207, 1998.

[9] D. Shukla, S. F. Nelson, D. C. Freeman, M. Rajeswaran, W. G. Ahearn, D. M. Meyer and J. T. Carey, "Thin-film morphology control in naphthalene-diimide-based semiconductors: High mobility n-type semiconductor for organic thin-film transistors," Chem. Mater., vol. 20, pp. 7486-7491, 2008.

[10] A. Opitz, M. Horlet, M. Kiwull, J. Wagner, M. Kraus, and W. Brütting, "Bipolar charge transport in organic field-effect transistors: Enabling high mobilities and transport of photo-generated charge carriers by a molecular passivation layer," Org. Electron., vol. 13, pp. 1641-1622, 2012.

[11] M. Kraus, S. Richler, A. Opitz, W. Brütting, S. Haas, T. Hasegawa, A. Hinderhofer, and F. Schreiber, "High-mobility copper-phthalocyanine field-effect transistors with tetratetracontane passivation layer and organic metal contacts," J. Appl. Phys., vol. 107, p. 094503, 2010.

[12] M. Kraus, S. Haug, W. Brütting, and A. Opitz, "Achievement of balanced electron andhole mobility in copper-phthalocyanine fieldeffect transistors by using a crystalline aliphatic passivation layer," Org. Electron., vol. 12, pp. 731-735, 2011.

[13] J. H. Seo, G. S. Chang, R. G. Wilks, C. N. Whang, K. H. Chae, S. Cho, K.-H. Yoo, and A. Moewes, "Unipolar-to-ambipolar conversion of organic thin-film transistors by organosilane self-assembled monolayer," J. Phys. Chem. B, vol. 112, pp. 16266-16270, 2008.

[14] (a) J. D. Yuen and F. Wudl, "Strong acceptors in donor-acceptor polymers for high performance thin film transistors," Energy Environ. Sci., vol. 6, pp. 392-406, 2013; (b) Y. Zhao, Y. Guo, and Y. Liu, "Recent Advances in n-Type and Ambipolar Organic Field-Effect Transistors," Adv. Mater., vol. 25, pp. 5372-5391, 2013; (c) Y. Olivier, D. Niedzialek, V. Lemaur, W. Pisula, K. Müllen, U. Koldemir, J. R. Reynolds, R. Lazzaroni, J. Cornil, and D. Beljonne, "High-mobility hole and electron transport conjugated polymers: How structure defines function," Adv. Mater., vol. 26, pp. 2119-2136, 2014; (d) E. Wang, W. Mammo, and M. R. Andersson, "Isoindigo-based polymers and small molecules for bulk heterojunction solar cells and field effect transistors," Adv. Mater., vol. 26, p. 182014.

[15] Z. Chen, M. J. Lee, R. S. Ashraf, Y. Gu, S. Albert-Seifried, M. M. Nielsen, B. Schroeder, T. Anthopoulos, M. Heeney, I. McCulloch, and H. Sirringhaus, "High-performance ambipolar 
diketopyrrolopyrrole-thieno[3,2-b] thiophene copolymer field-effect transistors with balanced hole and electron mobilities," Adv. Mater., vol. 24, pp. 647-652, 2012.

[16] R. J. Chesterfield, C. R. Newman, T. M. Pappenfus, P. C. Ewbank, M. H. Haukaas, K. R. Mann, L. L. Miller, and C. D. Frisbie, "High electron mobility and ambipolar transport in organic thin-film transistors based on a $\pi$-stacking quinoidal terthiophene," Adv. Mater., vol. 15, pp. 1278-1282, 2003.

[17] J. C. Ribierre, S. Watanabe, M. Matsumoto, T. Muto, and T. Aoyama, "Majority carrier type conversion in solution-processed organic transistors and flexible complementary logic circuits," Appl. Phys. Lett., vol. 96, p. 083303 , 2010.

[18] J. C. Ribierre, S. Ghosh, K. Takaishi, T. Muto, and T. Aoyama, "Influence of the gate dielectric on the ambipolar characteristics of solution-processed organic field-effect transistors," J. Phys. D, vol. 44, p. 205102, 2011.

[19] A. Tapponnier, I. Biaggio, and P. Günter, "Ultrapure $C_{60}$ field-effect transistors and the effects of oxygen exposure," Appl. Phys. Lett., vol. 86, p. 112114, 2005.

[20] T. D. Anthropoulos, C. Tanase, S. Setayesh, E. J. Meijer, J. C. Hummelen, P. W. M. Blom, and D. M. de Leeuw, "Ambipolar organic field-effect transistors based on a solution-processed methanofullerene," Adv. Mater., vol. 16, p. 2174, 2004.

[21] J. Kan, Y. Chen, D. Qi, Y. Liu, and J. Jiang, "High-performance air-stable ambipolar organic fieldeffect transistor based on tris(phthalocyaninato) europium(III)," Adv. Mater., vol. 24, pp. 1755-1758, 2012.

[22] T. Sakanoue, M. Yahiro, C. Adachi, K. Takimiya, and A. Toshimitsu, "Electrical characteristics of single-component ambipolar organic field-effect transistors and effects of air exposure on them," $J$. Appl. Phys., vol. 103, p. 094509, 2008.

[23] E. C. P. Smits, T. D. Anthopoulos, S. Setayesh, E. von Veenendaal, R. Coehoorn, P. W. M. Blom, B. de Boer, and D. M. de Leeuw, "Ambipolar charge transport in organic field-effect transistors," Phys. Rev. B, vol. 73, p. 205316, 2006.

[24] L.-Y. Chiu, H.-L. Cheng, H.-Y. Wang, W.-Y. Chou, and F.-C. Tang, "Manipulating the ambipolar characteristics of pentacene-based field-effect transistors," J. Mater. Chem. C, vol. 2, pp. 1823-1829, 2014.

[25] E. D. Głowacki, H. Coskun, M. A. Blood-Forsythe, U. Monkowius, L. Leonat, M. Grzybowski, D. Gryko, M. S. White, A. Aspuru-Guzik, and N. S. Sariciftci, "Hydrogen-bonded diketopyrrolopyrrole (DPP) pigments as organic semiconductors," Org. Electron., vol. 15, pp. 3521-3528, 2014.

[26] L. Serrano-Andrés, and B. O. Roos, "A Theoretical Study of the Indigoid Dyes and Their Chromophore," Chem. Eur. J., vol. 3, pp. 717-725, 1997.

[27] (a) G. R. Desiraju, "Reflections on the hydrogen bond in crystal engineering," Cryst. Growth Des., 11, 896-898, 2011; (b) J. Mizuguchi, "Correlation between crystal and electronic structures in diketopyrrolopyrrole pigments as viewed from exciton coupling effects," J. Phys. Chem. A., vol. 104, pp. 1817-1821, 2000.

[28] T. Odajima, M. Ashizawa, Y. Konosu, H. Matsumoto, and T. Mori, "The impact of molecular planarity on electronic devices in thienoisoindigo-based organic semiconductors," J. Mater. Chem. C, vol. 2, pp. 10455-10467, 2014.

[29] M. Irimia-Vlada, E. D. Głowacki, P. A. Troshin, G. Schwabegger, L. Leonat, D. K. Susarova, O. Krystal, M. Ullah, Y. Kanbur, M. A. Bodea, V. F. Razumov, H. Sitter, S. Bauer, and N. S. Sariciftci, "Indigo - A natural pigment for high performance ambipolar organic field effect transistors and circuits," Adv. Mater., vol. 24, pp. 375-380, 2012.

[30] E. D. Głowacki, G. Voss, and N. S. Sariciftci, "Progress in chemistry and applications of functional indigos for organic electronics," Adv. Mater., vol. 25, pp. 6783-6800, 2013.

[31] E. D. Głowacki, L. Lenonat, G. Voss, M. A. Bodea, Z. Buzkurt, A. M. Ramil, M. Irimia-Vlada, S. Bauer, and N. S. Sariciftci, "Ambipolar organic field effect transistors and inverters with the natural material Tyrian Purple," AIP Advances, vol. 1, p. 042132, 2011.

[32] E. D. Głowacki, D. H. Apaydin, Z. Bozkurt, U. Monkowius, K. Demirak, E. Tordin, M. Himmelsbach, C. Schwarzinger, M. Burin, R. T. Lechner, N. Demitri, G. Voss, and N. S. Sariciftci, 
"Air-stable organic semiconductors based on 6,6'-dithienylindigo and polymers thereof," J. Mater. Chem. C, vol. 2, pp. 8089-8097, 2014.

[33] O. Pitayatanakul, T. Higashino, T. Kadoya, M. Tanaka, H. Kojima, M. Ashizawa, T. Kawamoto, H. Matsumoto, K. Ishikawa, and T. Mori, "High performance ambipolar organic field-effect transistors based on indigo derivatives," J. Mater. Chem. C, vol. 2, pp. 9311-9317, 2014.

[34] V. Klimovich, L. I. Leshanskaya. S. I. Troyanov, D. V. Anokhin, D. V. Novikov, A. A. Piryazev, D. A. Ivanov, N. N. Dremova, and P. A. Troshin, "Design of indigo derivatives as environment-friendly organic semiconductors for sustainable organic electronics," J. Mater. Chem. C, vol. 2, pp. 7621-7631, 2014.

[35] (a) H. M. Yamamoto, J. Yamaura, and R. Kato, "Multicomponent molecular conductors with supramolecular assembly: Iodine-containing neutral molecules as building blocks," J. Am. Chem. Soc., vol. 120, 5905-5913, 1998; (b) H. M. Yamamoto, R. Maeda, J. Yamaura, and R. Kato, "Structural and physical properties of conductingcation radical salts containing supramolecular assemblies based on $p$ bis(iodoethynyl)benzenederivatives," J. Mater. Chem., vol. 11, pp. 1034-1041,2011.

[36] M. C. Burla, R. Caliandro, M. Camalli, B. Carrozzini, G. L. Cascarano, L. D. Caro, C. Giacovazzo, G. Polidori, D. Siliqi, and R. Spagna, "IL MILIONE: a suite of computer programs for crystal structure solution of proteins," J. Appl. Cryst., vol. 40, pp. 609-613, 2007.

[37] (a) M. Fourmigué and P. Batail, "Activation of hydrogen- and halogen-bonding interactions in tetrathiafulvalene-based crystalline molecular conductors," Chem. Rev., vol. 104, pp. 5379-5418, 2004; (b) M. Fourmigué, "Halogen bonding in conducting or magnetic molecular materials," Struct. Bonding, vol. 126, pp. 181-207, 2008; (c) J. Lieffrig, R. L. Pennec, O. Jeannin, P. Auban-Senzier, and M. Fourmigué, "Toward chiral conductors: combining halogen bonding ability and chirality within a single tetrathiafulvalene molecule," CrystEngComm, vol. 15, pp. 4408-4412, 2013; (d) T. Imakubo, H.

Sawa, and R. Kato, "Synthesis and properties of novel iodine-bonded $\pi$-donors containing selenium atoms, oxygen atoms or extended _-system," Synth. Met., vol. 86, pp. 1883-1884, 1997; (e) H. Shirahata, M. Kibune, M. Maesato, T. Kawashima, G. Saotp, and T. Imakubo, "New organic conductors based on dibromo- and diiodo-TSeFs with magnetic and non-magnetic $\mathrm{MX}_{4}$ counter anions $(\mathrm{M}=\mathrm{Fe}, \mathrm{Ga} ; \mathrm{X}$ = Cl, Br),"J. Mater. Chem., vol. 16, pp. 3381-3390, 2006.

[38] M. Ichikawa, H. Yanagi, Y Shimizu, S. Hotta, N. Suganuma, T. Koyama, and Y. Taniguchi, "Organic field-effect transistors made of epitaxially grown crystals of a thiophene/phenylene co-oligomer," Adv. Mater., vol. 14, pp. 1272, 2002.

[39] M. Mas-Torrent, P. Hadley, S. T. Bromley, N. Crivillers, J. Veciana, and C. Rovira, "Single-crystal organic field-effect transistors based on dibenzo-tetrathiafulvalene," Appl. Phys. Lett., vol. 86, p. 012110, 2005.

[40] S. Hotta and T. Yamao, "The thiophene/phenylene co-oligomers: exotic molecular semiconductors integrating high-performance electronic and optical functionalities," J. Mater. Chem., vol. 21, 1295-1304, 2011.

[41] B. Noda, M. Katsuhara, I. Aoyagi, T. Mori, T. Taguchi, T. Kambayashi, K. Ishikawa, and H. Takezoe, "Organic field-effect transistor based on biphenyl substituted TTF," Chem. Lett., vol. 34, pp. 392-393, 2005.

[42] M. L. Tang, A. D. Reichardt, P. Wei, and Z. Bao, "Correlating carrier type with frontier molecular orbital energy levels in organic thin film transistors of functionalized acene derivatives," J. Am. Chem. Soc., vol. 131, pp. 5264-5273, 2009.

[43] M. J. Frisch, G. W. Trucks, H. B. Schlegel, G. E. Scuseria, M. A. Robb, J. R. Cheeseman, G. Scalmani, V. Barone, B. Mennucci, G. A. Petersson, H. Nakatsuji,M. Caricato, X. Li,H.P. Hratchian, A. F. Izmaylov, J. Bloino, G. Zheng, J. L. Sonnenberg, M. Hada, M. Ehara, K. Toyota, R. Fukuda, J. Hasegawa, M. Ishida, T. Nakajima, Y. Honda, O. Kitao, H. Nakai, T. Vreven, J. A. Montgomery, Jr., J. E. Peralta, F. Ogliaro, M. Bearpark, J. J. Heyd, E. Brothers, K. N. Kudin, V. N. Staroverov, R. Kobayashi,J.Normand, K. Raghavachari, A. Rendell, J. C. Burant, S. S. Iyengar, J. Tomasi, M. Cossi, N. Rega, J. M. Millam, M. Klene, J. E. Knox, J. B. Cross, V. Bakken, C. Adamo, J. Jaramillo, R. Gomperts, R. E. Stratmann, O. Yazyev, A. J. Austin, R. Cammi,C. Pomelli, J. W. Ochterski, R. L. Martin, K. Morokuma, V. G. Zakrzewski, G. A. Voth, P. Salvador, J. J. Dannenberg, S. Dapprich, A. D. Daniels, O. Farkas, J. B. Foresman, J. V. Ortiz, J. Cioslowski, D. J. Fox, Gaussian 09 (Revision B. 01), Gaussian, Inc., Wallingford CT, 2009. 
[44] F. Kettner, L. Hüter, J. Schäfer, K. Röder, U. Purgahn, and H. Krautscheid, "Selective crystallization of indigo B by a modified sublimation method and its redetermined structure," Acta Crystallogr. sect E, vol. 67 , p. $2867,2011$.

[45] H. von Eller, "Structure de colorants indigoides. III. Structure cristalline de l'indigo," Bull. Soc. Chim. Fr., pp. 1433-1438, 1995.

[46] P. Süsse and A. Wolf, “A new crystalline phase of indigo," Naturwissenschaften, vol. 67, p. 453, 1980.

[47] P. Süsse, M. Steins and V. Kupcik, "Indigo: Crystal structure refinement based on synchrotron data," Z. Kristallogr., vol. 184, pp. 269-273, 1988.

[48] M. Yamada, R. Kanazawa and F. Hamada, "Halogen-halogen interaction and halogen bonding in thiacalixarene systems," CrystEngComm, vol. 16, pp. 2605-2614, 2014.

[49] T. Kakinuma, H. Kojima, M. Ashizawa, H. Matsumoto, and T. Mori, "Correlation of mobility and molecular packing in organic transistors based on cycloalkyl naphthalene diimides," J. Mater. Chem. C, vol. 1, pp. 5395-5401, 2013.

[50] H. Kojima and T. Mori, "Estimated mobility of ambipolar organic semiconductors, indigo and diketopyrrolopyrrole," Chem. Lett., vol. 42, pp. 68-70, 2013.

[51] M. Halik, H. Klauk, U. Zschieschang, G. Schmid, W. Radlik, and W. Weber, "Polymer gate dielectrics and conducting-polymer contactsfor high-performance organic thin-film transistors," Adv. Mater., vol. 14, pp. 1717-1722, 2002.

[52] Y. Jang, Y. D. Park, J. A. Lim, H. S. Lee, W. H. Lee, and K. Cho, "Patterning the organic electrodes of all-organic thin film transistors with a simple spray printing technique," Appl. Phys. Lett., vol. 89, p. $183501,2006$.

[53] S. R. Saudari, Y. J. Lin, Y. Lai, and C. R. Kagan, "Device configurations for ambipolar transport in flexible, pentacene transistors," Adv. Mater., vol. 22, pp. 5063-5068, 2010.

[54] J. Jakabovič, J. Kováč, M. Weis, D. Haško, R. Srnánek, P. Valent and R. Resel, "Preparation and properties of thin parylene layers as the gate dielectrics for organic field effect transistors," Microelectron. J., vol. 40, pp. 595-597, 2009. 